\title{
ELEVATED BLOOD PRESSURE AND ITS PREDICTORS AMONG SECONDARY SCHOOL STUDENTS IN SARAWAK: A CROSS-SECTIONAL STUDY
}

\author{
Woei Feng Grace Kho, Whye Lian Cheah, Helmy Hazmi \\ Department of Community Medicine and Public Health, Faculty of Medicine and Health Sciences, University of Malaysia, Sarawak, Malaysia
}

\section{SUMMARY}

Objectives: Hypertension is a health issue affecting adolescents. Accumulating evidence affirms that elevated blood pressure begins in childhood and tracks into adulthood. This cross-sectional study was conducted to determine the prevalence of elevated blood pressure and its predictors among secondary school students in Sarawak, Malaysia.

Methods: A total of 2,461 secondary school students aged 12-17 years from 19 schools in Sarawak participated in the study. Questionnaire was used to obtain socio-demographic data, parental history of hypertension, and self-reported physical activity. Anthropometric and blood pressure measurements were taken. Data was entered and analysed using SPSS version 23.0.

Results: The prevalence of adolescents with elevated blood pressure, overweight, central obesity, and overfat were $30.1 \%, 24.3 \%, 13.5 \%$, and $6.7 \%$, respectively. Multivariate logistic regression demonstrated the predictors significantly associated with elevated blood pressure among respondents: overweight (adjusted odds ratio $=3.144$ ), being male (adjusted odds ratio $=3.073$ ), being Chinese (adjusted odds ratio $=2.321$ ) or Iban (adjusted odds ratio $=1.578$ ), central obesity (adjusted odds ratio $=2.145$ ), being overfat (adjusted odds ratio $=1.885$ ), and being an older adolescent (adjusted odds ratio $=1.109$ ). Parental history of hypertension, locality, and physical activity showed no significant associations.

Conclusion: The obesity epidemic must be tackled at community and school levels by health education and regulation of school canteen foods.

Key words: adolescent, elevated blood pressure, hypertension, prevalence, predictors, risk factors, obesity, gender, ethnic, age, parental history of hypertension, locality, urban, rural, physical activity, Sarawak, Malaysia

Address for correspondence: Whye Lian Cheah, Department of Community Medicine and Public Health, Faculty of Medicine and Health Sciences, University of Malaysia Sarawak, 94300 Kota Samarahan, Sarawak, Malaysia. E-mail: wlcheah@unimas.my

https://doi.org/10.21101/cejph.a5186

\section{INTRODUCTION}

Elevated blood pressure (BP) or hypertension has been frequently implicated as an exceptionally common and weighty risk factor of cardiovascular and renal diseases, including stroke, coronary heart disease, heart failure, left ventricular hypertrophy, and kidney failure (1). This is a major concern as prevalence of hypertension seems to be on an upward trend worldwide. Globally, the overall prevalence of elevated BP in adults aged more than 24 years was around $40 \%$ or nearly 1 billion in 2008 , an upsurge from 600 million in 1980 (1). By 2025, this number is expected to reach 1.56 billion (2). In Malaysia, the latest statistics by the National Health and Morbidity Survey (NHMS) 2015 displayed that $30.3 \%$ or around one-third of adults aged 18 years and above were hypertensive (3). The high global prevalence of elevated $\mathrm{BP}$ has led to an estimated 7.5 million deaths, which was about $12.8 \%$ of all deaths (1).

Even more worryingly, recent studies have found that hypertension is no longer a health issue exclusive to adults, as it is becoming progressively common among adolescents (2). As a matter of fact, accumulating evidence affirms that elevated BP begins in childhood and tracks into adulthood (4). In 1995, Bao et al. analysed data from the renowned Bogalusa Heart Study
(BHS) and found that elevated BP levels in childhood tend to persist into adulthood independent of body mass index (BMI), with double the expected number of individuals whose levels were in the highest quintile at childhood remaining there in adulthood 15 years later (5).

In light of this phenomenon, there is growing interest in the prevalence of elevated BP among adolescents. The results of present studies have been inconsistent. There was a national study on the prevalence of adolescent hypertension conducted in the United States (6), which was not directly applicable in the Malaysian settings due to the wide range of prevalence reported and differences in the biology of Asians and Americans. Unfortunately, to our knowledge only two studies related to adolescent BP have been done in Malaysia. Both studies used the International Diabetes Federation (IDF) standard to define adolescent hypertension as they focused on metabolic syndrome rather than hypertension alone $(7,8)$. However, the prevalence of adolescent hypertension is better determined by the BP standards of the National High Blood Pressure Education Program (NHBPEP) (9). Thus, the present study was designed to fill in the gap in knowledge on the prevalence of elevated BP among adolescents in the state of Sarawak, Malaysia, and its predictors so early actions can be taken before adolescent elevated $\mathrm{BP}$ becomes adult hypertension. 


\section{MATERIALS AND METHODS}

To ensure the adolescent population in the whole of Sarawak was adequately represented, all Sarawak government schools were classified by locality according to the Ministry of Education (MOE) database and then by district according to the Sarawak Government database. The probability of a school being selected was calculated based on the size of its enrolment in relation to the total enrolment for the state and the number of schools needed for the study. Nineteen selected schools agreed to participate in this study, of which 14 were categorised as rural while 5 were categorised as urban. Informed consent was obtained from participants in every school included in this study. Only students aged 12-17 years without conditions that could cause secondary hypertension including hyperthyroidism (9) or antihypertensive medicine prescriptions were allowed to participate. Among the 2,540 students who gave consent, 79 (3.1\%) were excluded as they did not meet the inclusion or exclusion criteria.

Data collection was conducted for 7 months from 9th March 2016 to 27th September 2016. A bilingual (Malay and English) questionnaire was used to obtain socio-demographic data including age in years (according to birth date), ethnic (paternal ethnic if parents were of different ethnics), gender, medical history, and parental history of hypertension. Physical activity level was also derived from the questionnaire. On the other hand, the clinically validated Omron HBP-1300 BP monitor was used to measure $\mathrm{BP}$, the Seca 213 stadiometer was used to measure height, nonextensible tapes to measure waist circumference (WC), and the Omron HBF-375 body composition monitor to measure weight and body fat percentage. Measurement protocols were conducted based on guidelines $(9,10)$ and approved by the University of Malaysia, Sarawak (UNIMAS) Medical Ethics Committee, the Malaysian Ministry of Education, and the Sarawak Ministry of Education. Respondents with elevated BP were advised to visit a doctor. Data was analysed in SPSS version 23.0.

Elevated BP was defined as BP that fell within the prehypertension, stage I hypertension, and stage II hypertension classifications according to the standards provided by the NHBPEP (9). The term 'elevated BP' instead of hypertension was used because BP measurement on more than 1 occasion (preferably on 3 separate occasions) was needed to clinically diagnose hypertension in adolescence due to white-coat hypertension, the accommodation effect, and the regression to mean statistical change (9). On the other hand, respondents with BP in the prehypertensive range were classified with elevated BP rather than normal because white-coat hypertension and prehypertension might not be completely harmless but an intermediate stage between normal BP and hypertension (11).

Waist circumference (WC) was defined using the reference tables for Malaysian adolescents based on age and gender (10). WC above 90th percentile based on age and gender was classified as centrally obese. It was noted that the reference tables only gave references up to 16.9 years of age. However, the same standards ( $90.2 \mathrm{~cm}$ for male, $80.8 \mathrm{~cm}$ for female) for 16 years old were used for adolescents aged 17 years as they were already higher than the international cut-off point for Asian adults, which are $90 \mathrm{~cm}$ for males and $80 \mathrm{~cm}$ for females (12).

Using the height and weight data obtained, BMI was computed from dividing the respondent's weight $(\mathrm{kg})$ by the square of his/ her height $\left(\mathrm{m}^{2}\right)$. BMI classification was based on the Centers for Disease Control and Prevention (CDC) BMI-for-age growth charts based on age and gender. $\mathrm{CDC}$ recommends classification of BMI into underweight, normal, overweight, and obese (13). To simplify data interpretation in tests for associations, BMI was classified into normal (below 85th percentile) and overweight (at or above 85 th percentile) only.

Body fat percentage was classified into underfat, standard minus, standard plus, overfat, and obese according to Tanita's body fat percentage reference table for Asian adolescents based on age and gender (14). In tests for associations, the classifications were simplified into normal (including underfat, standard minus, and standard plus) and overfat (including overfat and obese).

Physical activity level was determined by obtaining the frequency and duration of physical activities each respondent usually carried out in a week. The frequency and duration were multiplied with the physical activities metabolic equivalent (MET) value derived from the 2011 Compendium of Physical Activities: A Second Update of Codes and MET (15). From there, the METminutes per day were calculated. Respondents were classified as active if they achieved a minimum of 600 MET-minutes per day and inactive for MET-minutes per day below 600 (16).

Researchers carried out multivariate logistic regression firstly on the significant predictors selected by chi-squared test or univariate logistic regression (which yielded the same significant predictors as chi-squared test) and then once again on all potential

Table 1. Socio-demographic characteristics of respondents $(N=2,461)$

\begin{tabular}{|c|c|c|c|}
\hline Characteristics & $\mathrm{n}(\%)$ & Mean (SD) & Range \\
\hline Age in years $(n=2,461)$ & & $14.5(1.50)$ & $12-17$ \\
\hline 12 & $255(10.4)$ & & \\
\hline 13 & $532(21.6)$ & & \\
\hline 14 & $476(19.3)$ & & \\
\hline 15 & $461(18.7)$ & & \\
\hline 16 & $522(21.2)$ & & \\
\hline 17 & $215(8.7)$ & & \\
\hline \multicolumn{4}{|l|}{ Gender $(n=2,461)$} \\
\hline Male & $1,033(42.0)$ & & \\
\hline Female & $1,428(58.0)$ & & \\
\hline \multicolumn{4}{|l|}{ Ethnic $(n=2,439)$} \\
\hline Iban & $725(29.7)$ & & \\
\hline Malay & $673(27.6)$ & & \\
\hline Chinese & $475(19.5)$ & & \\
\hline Bidayuh & $255(10.5)$ & & \\
\hline Others & $311(12.8)$ & & \\
\hline \multicolumn{4}{|l|}{ Locality $(n=2,461)$} \\
\hline Urban & $633(25.7)$ & & \\
\hline Rural & $1,828(74.3)$ & & \\
\hline \multicolumn{4}{|c|}{ Parental history of hypertension $(n=2,461)$} \\
\hline No history & $1,933(78.5)$ & & \\
\hline One hypertensive parent & $448(18.2)$ & & \\
\hline Two hypertensive parents & $80(3.3)$ & & \\
\hline
\end{tabular}


predictors. It was found that the final model with higher classification accuracy $(76.1 \%$ as opposed to $75.7 \%)$ was the one that included all potential predictors. All the potential predictors were analysed as categorical independent variable except age, which was analysed as continuous independent variable. The dependent variable BP status was categorical. In all analyses, p-value less than 0.05 was considered significant.

\section{RESULTS}

Total of 2,461 respondents ( $42 \%$ males and $58 \%$ females) aged 12 to 17 years from 19 schools all over Sarawak participated in this study. Iban made up the largest ethnic among the respondents, followed by Malay, Chinese, other ethnics, and Bidayuh. Other ethnic groups consisting of Melanau, Lun Bawang, Kenyah, Murut, Kelabit, Kedayan, Indian, Kadazan, Bisaya, Kenyan, Kiput, Bajau, Berawan, Penan, Punan, Dusun, Punjabi, Javanese, and Lahanan were combined together due to their low number of respondents (less than 5.0\%). 22 respondents did not identify with any ethnic (Table 1).

Prevalence of elevated BP was $30.1 \%$ while prevalence of obesity according to BMI, WC and body fat percentage was $24.3 \%, 13.5 \%$, and $6.7 \%$, respectively. Both mean systolic and mean diastolic BPs were in the normal range (Table 2).

Chi-squared test was used to determine the distribution of respondents for each potential predictor according to BP status (Table 3).
Results of multivariate logistic regression showed that the predictors significantly associated with BP status of respondents at $95 \%$ confidence interval were BMI, gender, ethnic, WC, body fat percentage, and age (Table 4).

\section{DISCUSSION}

To our knowledge, this is the first study focusing on adolescent BP in Malaysia, especially in the state of Sarawak. The previous two related Malaysian studies investigated metabolic syndrome rather than adolescent BP only $(7,8)$. In those two studies, the prevalence of elevated BP found were $35.5 \%$ and $38.0 \%$ (7, 8). In comparison, the prevalence found in this study was only $30.1 \%$. However, this study was not directly comparable to the above studies due to different standards used to define elevated BP in adolescents. The IDF standard of $130 / 85 \mathrm{~mm} \mathrm{Hg}$ was used in those studies as their primary interest was metabolic syndrome and not BP alone. The NHBPEP standards stratified by gender, age, and height percentile (9) were used in this study as it was more accurate in diagnosing adolescent elevated BP.

However, this does not explain the relatively higher prevalence of elevated BP in those studies as the IDF cut-off point was much higher than the highest cut-off point $(120 / 80 \mathrm{~mm} \mathrm{Hg})$ of the NHBPEP standards. Thus, we investigated deeper and observed that in both studies, the obesity rate was much higher. One study had $100 \%$ overweight rate as indicated by BMI and $91.3 \%$ central obesity rate as indicated by WC (7), as compared

Table 2. Nutritional characteristics of respondents $(N=2,461)$

\begin{tabular}{|c|c|c|c|}
\hline Characteristics & $\mathrm{n}(\% \mathrm{a})$ & Mean (SD) & Min-Max \\
\hline \multicolumn{4}{|l|}{ Physical activity $(n=2,432)$} \\
\hline Inactive & $1,400(57.6)$ & & \\
\hline Active & $1,032(42.4)$ & & \\
\hline BMI in $\mathrm{kg} \mathrm{m}^{-2}(n=2,461)$ & & $21.5(4.76)$ & $13.1-43.5$ \\
\hline Underweight & $149(6.1)$ & & \\
\hline Normal & $1,714(69.6)$ & & \\
\hline Overweight & $303(12.3)$ & & \\
\hline Obese & $295(12.0)$ & & \\
\hline Waist circumference in $\mathrm{cm}(\mathrm{n}=2,461)$ & & $70.6(15.94)$ & $50.0-125.0$ \\
\hline Normal & $2,128(86.5)$ & & \\
\hline Centrally obese & $333(13.5)$ & & \\
\hline Body fat percentage in $\%^{b}(n=2,461)$ & & $21.1(6.82)$ & $<5.0-39.0$ \\
\hline Underfat & $51(2.1)$ & & \\
\hline Normal & $2,245(91.2)$ & & \\
\hline Overfat & $128(5.2)$ & & \\
\hline Obese & $37(1.5)$ & & \\
\hline Systolic BP in mm Hg $(n=2,461)$ & & $114.1(13.26)$ & $73.0-177.0$ \\
\hline Diastolic BP in mm Hg $(n=2,461)$ & & $65.5(9.28)$ & $40.0-117.0$ \\
\hline \multicolumn{4}{|l|}{ BP status $(n=2,461)$} \\
\hline Normal & $1,720(69.9)$ & & \\
\hline Elevated & $741(30.1)$ & & \\
\hline
\end{tabular}


Table 3. Distribution of respondents by BP status for each potential predictor $(N=2,461)$

\begin{tabular}{|c|c|c|}
\hline Predictor & $\begin{array}{c}\text { Normal } \\
\mathrm{n}(\%)\end{array}$ & $\begin{array}{c}\text { Elevated BP } \\
\mathrm{n}(\%)\end{array}$ \\
\hline \multicolumn{3}{|l|}{ Age in years } \\
\hline 12 & $183(71.8)$ & $72(28.2)$ \\
\hline 13 & $378(71.1)$ & $154(28.9)$ \\
\hline 14 & $340(71.4)$ & $136(28.6)$ \\
\hline 15 & $320(69.4)$ & $141(30.6)$ \\
\hline 16 & $353(67.6)$ & $169(32.4)$ \\
\hline 17 & $146(67.9)$ & $69(32.1)$ \\
\hline \multicolumn{3}{|l|}{ Gender } \\
\hline Male & $602(58.3)$ & $431(41.7)$ \\
\hline Female & $1,118(78.3)$ & $310(21.7)$ \\
\hline \multicolumn{3}{|l|}{ Ethnic } \\
\hline Iban & $491(67.7)$ & $234(32.3)$ \\
\hline Malay & $493(73.3)$ & $180(26.7)$ \\
\hline Chinese & $289(60.8)$ & $186(39.2)$ \\
\hline Bidayuh & $198(77.6)$ & $57(22.4)$ \\
\hline Others & $229(73.6)$ & $82(26.4)$ \\
\hline \multicolumn{3}{|l|}{ Locality } \\
\hline Urban & $415(65.6)$ & $218(34.4)$ \\
\hline Rural & $1,305(71.4)$ & $523(28.6)$ \\
\hline \multicolumn{3}{|c|}{ Parental history of hypertension } \\
\hline No history & $1,381(71.4)$ & $552(28.6)$ \\
\hline One hypertensive parent & $293(65.4)$ & $155(34.6)$ \\
\hline Two hypertensive parents & $46(57.5)$ & $34(42.5)$ \\
\hline \multicolumn{3}{|l|}{ Physical activity } \\
\hline Inactive & $986(70.4)$ & $414(29.6)$ \\
\hline Active & $713(69.1)$ & $319(30.9)$ \\
\hline \multicolumn{3}{|l|}{ BMI } \\
\hline Normal & $1,467(78.7)$ & $396(21.3)$ \\
\hline Overweight & $253(42.3)$ & $345(57.7)$ \\
\hline \multicolumn{3}{|l|}{ Waist circumference } \\
\hline Normal & $1,604(75.4)$ & $524(24.6)$ \\
\hline Centrally obese & $116(34.8)$ & $217(65.2)$ \\
\hline \multicolumn{3}{|l|}{ Body fat percentage } \\
\hline Normal & $1,682(73.3)$ & $614(26.7)$ \\
\hline Overfat & $38(23.0)$ & $127(77.0)$ \\
\hline
\end{tabular}

$\mathrm{BP}$ - blood pressure; $\mathrm{BMI}$ - body mass index

to only $24.3 \%$ and $13.5 \%$ in this study. $36.9 \%$ of the respondents of the other study was centrally obese with WC cut-off points of $90 \mathrm{~cm}$ or more for males and $80 \mathrm{~cm}$ or more for female (8). Relatively higher obesity rates probably contributed to the higher prevalence of elevated BP, in line with the finding of this study.

All three obesity indices (BMI, WC, body fat percentage) demonstrated highly significant associations with adolescent elevated BP, with BMI being the most significant predictor among all predictors investigated in this study. This result concurs with previous literature that obesity is one of the most important modifiable predictor of elevated BP in adolescents, if not the most important $(4,6,9,17,18)$. In fact, the increase in prevalence of adolescent hypertension in the past few decades have been attributed to the increase in prevalence of adolescent overweight and obesity (18), with the trajectory of increase in adolescent BP parallel to but lagging behind the adolescent obesity epidemic by about 10 years $(6,19)$. This association has been observed as early as in the first year of life (20), and seems to grow more evident in the second year of life (21).

Among the three obesity indices studied, BMI showed the strongest association, followed by WC, and body fat percentage. WC is often postulated as a better predictor as it estimates intraabdominal body fat and visceral fat depots are assumed to secrete more free fatty acids (FFA) and proinflammatory cytokines than subcutaneous compartments $(21,23)$. However, it appears that visceral fat has very little if any role in the oversupply of FFAs to extrahepatic tissues in insulin-resistant states (24). In addition, visceral fat only makes up a relatively small proportion of intraabdominal fat in adolescents as compared to adults, so it is less physiologically important for adolescents (25). Insulin resistance has also been found to be more strongly associated with total fat mass and BMI rather than intraabdominal fat only (24). It must also be remembered that WC is only an estimation of intraabdominal fat, explaining only up to $64 \%$ of its variance in children aged 7-16 years, and there are significant differences between ethnics and genders in its estimation (26). Meanwhile, body fat percentage was the weakest predictor as compared to $\mathrm{BMI}$ and $\mathrm{WC}$, consistent with previous findings using the bioelectric impedance method (27) or the dual-energy X-ray absorptiometry (DEXA) method (28).

Gender and age are well-established predictors of adolescent BP status $(4,6,17)$. In this study, male adolescents were about three times more likely than female adolescents to have elevated BP while the likelihood of an adolescent to have elevated BP increased by around 1.1 time per year of age.

In terms of ethnic, Chinese adolescents were more than twice as likely than Bidayuh (the ethnic with the lowest prevalence of elevated BP) to have elevated BP while Iban was about 1.5 times more likely than Bidayuh to have elevated BP. A possible explanation was that Iban and Chinese respondents had the highest obesity prevalence among the ethnics. Oddly though, Malays had the highest prevalence of obesity with body fat percentage as index, but our study had demonstrated that body fat percentage was the weakest obesity index in relation to BP status. Additionally, more than half of the Chinese respondents came from urban areas, which more than doubled the second ethnic with the most urban respondents. The urban setting has been significantly associated with adolescent hypertension in previous literature (29).

Both parental history of hypertension and locality demonstrated significant associations with respondents' BP status only in univariate analysis, implying that their associations with adolescent BP status were mediated by other predictors such as obesity and physical activity.

The association between physical activity and adolescent BP in literature has been conflicting, with certain studies reporting significant association while some studies found none (30). In this study, no association was found by either multivariate or univariate analysis. 
Table 4. Significance and strength of associations between potential predictor and BP status of respondents $(N=2,461)$

\begin{tabular}{|c|c|c|c|c|c|c|}
\hline Predictor & B & SE & $\begin{array}{l}\text { Crude OR } \\
(95 \% \mathrm{Cl})\end{array}$ & В & SE & $\begin{array}{c}\text { Adjusted OR } \\
(95 \% \mathrm{Cl})\end{array}$ \\
\hline \multicolumn{7}{|l|}{ BMl } \\
\hline Overweight (reference = normal) & $1.620^{\star * *}$ & 0.100 & $5.052(4.149,6.135)$ & $1.145^{\star \star *}$ & 0.144 & $3.144(2.375,4.149)$ \\
\hline \multicolumn{7}{|l|}{ Gender } \\
\hline Male (reference = female) & $0.949^{\star \star *}$ & 0.090 & $2.582(2.164,3.080)$ & $1.123^{* * *}$ & 0.108 & $3.073(2.553,3.860)$ \\
\hline \multicolumn{7}{|l|}{ Ethnic } \\
\hline Chinese & $0.805^{\star \star *}$ & 0.177 & $2.236(1.555,3.105)$ & $0.842^{* * *}$ & 0.203 & $2.321(1.610,3.506)$ \\
\hline Iban & $0.504^{* *}$ & 0.170 & $1.655(1.148,2.225)$ & $0.456^{*}$ & 0.187 & $1.578(1.133,2.317)$ \\
\hline Others & 0.218 & 0.198 & $1.244(0.827,1.721)$ & 0.217 & 0.217 & $1.243(0.893,2.048)$ \\
\hline Malay & 0.238 & 0.174 & $1.268(0.827,1.791)$ & 0.109 & 0.193 & $1.115(0.796,1.663)$ \\
\hline Overall (reference $=$ Bidayuh) & *** & & & *** & & \\
\hline \multicolumn{7}{|l|}{ Waist circumference } \\
\hline Centrally obese (reference $=$ normal) & $1.745^{\star \star \star}$ & 0.126 & $5.726(4.484,7.299)$ & $0.763^{\star \star *}$ & 0.192 & $2.145(1.623,3.194)$ \\
\hline \multicolumn{7}{|l|}{ Body fat percentage } \\
\hline Overfat $($ reference $=$ normal $)$ & $2.214^{* * *}$ & 0.191 & $9.155(6.289,13.333)$ & $0.634^{* *}$ & 0.232 & $1.885(1.224,3.030)$ \\
\hline Age in years & 0.047 & 0.029 & $1.048(0.989,1.110)$ & $0.103^{* *}$ & 0.033 & $1.109(1.031,1.172)$ \\
\hline \multicolumn{7}{|l|}{ Parental history of hypertension } \\
\hline Two hypertensive parents & $0.615^{* *}$ & 0.232 & $1.849(1.174,2.912)$ & 0.373 & 0.269 & $1.452(0.941,2.628)$ \\
\hline One hypertensive parent & $0.280^{*}$ & 0.111 & $1.323(1.064,1.646)$ & 0.220 & 0.128 & $1.247(1.034,1.693)$ \\
\hline Overall (reference = no history) & ** & & & & & \\
\hline \multicolumn{7}{|l|}{ Locality } \\
\hline Urban (reference = rural) & $0.271^{* *}$ & 0.098 & $1.311(1.088,1.600)$ & 0.136 & 0.118 & $1.146(0.951,1.497)$ \\
\hline \multicolumn{7}{|l|}{ Physical activity } \\
\hline Active (reference = inactive) & 0.064 & 0.089 & $1.066(0.787,1.115)$ & -0.100 & 0.103 & $0.905(0.811,1.355)$ \\
\hline \multicolumn{4}{|l|}{ Constant } & $-3.768^{* * *}$ & 0.533 & 0.023 \\
\hline \multicolumn{4}{|l|}{ Model chi-squared } & \multicolumn{3}{|c|}{$466.803^{* * *}, \mathrm{df}=13$} \\
\hline \multicolumn{4}{|l|}{ Hosmer and Lemeshow test } & \multicolumn{3}{|c|}{$p$-value $>0.05$} \\
\hline Classification accuracy & \multicolumn{3}{|c|}{$69.7-74.0 \%$} & \multicolumn{3}{|c|}{$76.1 \%$} \\
\hline
\end{tabular}

\section{CONCLUSIONS}

The prevalence of elevated BP found in this study was $30.1 \%$, i.e. lower than in other local studies. Obesity, measured by BMI, WC or body fat percentage, was predictor of elevated blood pressure, consistent with the global trends. Besides that, age, gender and ethnicity were also significant predictors of elevated BP. The findings of this study can aid to the identification of adolescents at high risk of hypertension so early treatment can be taken. Awareness on the severity of elevated BP and obesity among Sarawakian adolescents should be raised so appropriate actions can be done on both community and school levels such as health education, regulation of school canteen foods, and instating a nutritionist in every school. The ethnic differences, diet, and lifestyle of Sarawakian adolescents deserve further investigation.

\section{Acknowledgements}

We would like to thank the Ministry of Higher Education, Ministry of Education for making this study successful.
This study was supported by the Fundamental Research Grant Scheme, the Malaysia Ministry of Higher Education.

\section{Conflict of Interests}

None declared

\section{REFERENCES}

1. World Health Organisation [Internet]. Geneva: WHO; 2017 [cited 2017 Mar 22]. Global Health Observatory (GHO) data: raised blood pressure. Available from: http://www.who.int/gho/ncd/risk_factors/blood pressure_prevalence_text/en/.

2. The Lancet. Hypertension: uncontrolled and conquering the world. Lancet. 2007;370(9587): 539.

3. Institute for Public Health. National Health and Morbidity Survey 2015. Vol. II: non-communicable diseases, risk factors \& other health problems. Kuala Lumpur: Ministry of Health Malaysia, National Institutes of Health, Institute for Public Health; 2015.

4. Falkner B. Hypertension in children and adolescents: epidemiology and natural history. Pediatr Nephrol. 2010;25(7):1219-24. 
5. Bao W, Threefoot SA, Srinivasan SR, Berenson GS. Essential hypertension predicted by tracking of elevated blood pressure from childhood to adulthood: the Bogalusa Heart Study. Am J Hypertens. 1995;8(7):657-65.

6. Din-Dzietham R, Liu Y, Bielo MV, Shamsa F. High blood pressure trends in children and adolescents in national surveys, 1963 to 2002. Circulation. 2007;116(13):1488-96.

7. Muhammad Yazid J, Aisha Fadhilah AA, Noorasekin S, Nurshadia S, Zahurin M, Fatimah H. One in five overweight / obese adolescents in the community has metabolic syndrome. JUMMEC. 2013;16(2): 52-3.

8. Rampal S, Mahadeva S, Guallar E, Bulgiba A, Mohamed R, Rahmat R, et alEthnic differences in the prevalence of metabolic syndrome: results from a multi-ethnic population-based survey in Malaysia. PLoS One. 2012;7(9):e46365. doi: 10.1371/journal.pone.0046365.

9. National High Blood Pressure Education Program Working Group on Children and Adolescents. The fourth report on the diagnosis, evaluation, and treatment of high blood pressure in children and adolescents. Pediatrics. 2004;114(2 Suppl 4th Report):555-76.

10. Poh BK, Jannah AN, Chong LK, Ruzita AT, Ismail MN, McCarthy D Waist circumference percentile curves for Malaysian children and adolescents aged 6.0-16.9 years. Int J Pediatr Obes. 2011;6(3-4):229-35.

11. Gustavsen PH, Hoegholm A, Bang LE, Kristensen KS. White coat hypertension is a cardiovascular risk factor: a 10-year follow-up study. J Hum Hypertens. 2003;17(12):811-7.

12. Alberti KG, Eckel RH, Grundy SM, Zimmet PZ, Cleeman JI, Donato KA, et al. Harmonizing the Metabolic Syndrome: A Joint Interim Statement of the International Diabetes Federation Task Force on Epidemiology and Prevention; National Heart, Lung, and Blood Institute; American Heart Association; World Heart Federation; International Atherosclerosis Society; and International Association for the Study of Obesity. Circulation. 2009;120(16):1640-5.

13. Kuczmarski RJ, Ogden CL, Guo SS, Grummer-Strawn LM, Flegal KM, Mei Z, et al. 2000 CDC Growth Charts for the United States: methods and development. Vital Health Stat 11. 2002 May;(246):1-190.

14. Tanita. Asian Healthy Body Fat Ranges for Children. [Internet]. Hong Kong: Tanita; 2011 [cited 2015 Nov 24]. Available from: http://www. tanita.co.kr/download/ Body_Fat_Ranges for Children. Body_Fat and Visceral Fat Section.pdf.

15. Ainsworth BE, Haskell WL, Herrmann SD, Meckes N, Bassett DR Jr, Tudor-Locke C, et al. 2011 Compendium of Physical Activities: a second update of codes and MET values. Med Sci Sports Exerc. 2011;43(8):157581.

16. Institute for Public Health. National Health and Morbidity Survey 2015. Vol. II: non-communicable diseases, risk factors \& other health problems Kuala Lumpur: Ministry of Health Malaysia, National Institutes of Health, Institute for Public Health; 2015.

17. Dasgupta K, O’Loughlin J, Chen S, Karp I, Paradis G, Tremblay J, et al. Emergence of sex differences in prevalence of high systolic blood pressure: analysis of a longitudinal adolescent cohort. Circulation. 2006;114(24):2663-70.
18. Moyer VA; U.S. Preventive Services Task Force. Screening for primary hypertension in children and adolescents: U.S. Preventive Services Task Force recommendation statement. Pediatrics. 2013;132(5):907-14

19. Kelly RK, Magnussen CG, Sabin MA, Cheung M, Juonala M. Development of hypertension in overweight adolescents: a review. Adolesc Health Med Ther. 2015;6:171-87.

20. Burke V, Beilin LJ, Simmer K, Oddy WH, Blake KV, Doherty D, et al Predictors of body mass index and associations with cardiovascular risk factors in Australian children: a prospective cohort study. Int J Obes. 2005;29(1):15-23.

21. Vogt BA. Hypertension in children and adolescents: definition, pathophysiology, risk factors, and long-term sequelae. Curr Ther Res. 2001;62(4):283-97.

22. Lee S, Bacha F, Arslanian SA. Waist circumference, blood pressure, and lipid components of the metabolic syndrome. J Pediatr. 2006;149(6):80916.

23. Després JP. Is visceral obesity the cause of the metabolic syndrome? Ann Med. 2006;38(1):52-63.

24. Miles JM, Jensen MD. Counterpoint: visceral adiposity is not causally related to insulin resistance. Diabetes Care. 2005;28(9):2326-28.

25. Tershakovec AM, Kuppler KM, Zemel BS, Katz L, Weinzimer S, Harty MP, et al. Body composition and metabolic factors in obese children and adolescents. Int J Obes Relat Metab Disord. 2003;27(1):19-24.

26. Brambilla P, Bedogni G, Moreno LA, Goran MI, Gutin B, Fox KR, et al. Crossvalidation of anthropometry against magnetic resonance imaging for the assessment of visceral and subcutaneous adipose tissue in children. Int J Obes. 2006;30(1):23-30.

27. Rao S, Kanade A, Kelkar R. Blood pressure among overweigh adolescents from urban school children in Pune, India. Eur J Clin Nutr. 2007;61(5):633-41.

28. Fernandes RA, Christofaro DG, Buonani C, Monteriro HL, Cardoso JR, Freitas IF Jr, et al. Performance of body fat and body mass index cutoffs in elevated blood pressure screening among male children and adolescents. Hypertens Res. 2011;34(8):963-7.

29. Yamamoto-Kimura L, Posadas-Romero C, Posadas-Sánchez R, ZamoraGonzález J, Cardoso-Saldaña G, Méndez Ramírez I. Prevalence and interrelations of cardiovascular risk factors in urban and rural Mexican adolescents. J Adolesc Health. 2006;38(5):591-8.

30. Parkhad SB, Palve SB. Association of physical activity and physical fitness with blood pressure profile in Maharashtrian adolescent boys and girls. Internet Journal of Medical Update. 2014;9(1):4-9. 